\title{
Article \\ Application of Game Theory against Nature in Supporting Bid Pricing in Construction
}

\author{
Łukasz Rzepecki *(D) and Piotr Jaśkowski \\ Faculty of Civil Engineering and Architecture, Lublin University of Technology, 40 Nadbystrzycka St, \\ 20-618 Lublin, Poland; p.jaskowski@pollub.pl \\ * Correspondence: 1.rzepecki@pollub.pl
}

check for updates

Citation: Rzepecki, Ł.; Jaśkowski, P. Application of Game Theory against Nature in Supporting Bid Pricing in Construction. Symmetry 2021, 13, 132. https://doi.org/10.3390/ sym13010132

Received: 10 December 2020 Accepted: 11 January 2021 Published: 14 January 2021

Publisher's Note: MDPI stays neutral with regard to jurisdictional clai$\mathrm{ms}$ in published maps and institutional affiliations.

Copyright: (C) 2021 by the authors. Licensee MDPI, Basel, Switzerland. This article is an open access article distributed under the terms and conditions of the Creative Commons Attribution (CC BY) license (https:// creativecommons.org/licenses/by/ $4.0 /)$.

\begin{abstract}
The problem of setting prices for construction works is significant for both the investor and contractor companies. The periodically occurring instabilities in the economy require investment process participants to perform detailed market analyses and assessments, as well as to monitor price forecasts in construction. It is only after such an assessment that it is possible within the framework of the initial assumptions for cost calculation to select the basis for setting prices and their levels. The identification and analysis of the risks related to uncontrolled price increases allow contractors to secure their businesses by developing bids that ensure maximum profit. In view of the above, this study proposes an approach based on the use of game theory against nature to identify the optimal variant of a bid estimate. The study considers price forecasts for construction products, which may reduce the negative impact in case the prices increase. The obtained results confirmed the effectiveness of the used decision-making support methods, indicating the optimal strategy to reduce financial losses in times of market instability. The proposed approach also allows for a balance (symmetry) between maximum profit and probability of winning the contract.
\end{abstract}

Keywords: bid price predicting; civil engineering; construction company marketing; construction project management; cost management; decision-making methods; game theory

\section{Introduction}

Forecasting economic phenomena is one of the methods used for minimizing the impact of risk factors involved in business activities. It is also a way to increase competitiveness among other market participants. Price forecasts are particularly important for construction companies, assisting them in preparing their long-term projects or employment plans.

Econometric models constitute an effective tool for forecasting prices in construction. When estimating the prices of construction products, linear autoregression models with lagged values of a response variable are most commonly used. These models allow one to take into account the variability in the relation time between variables. The price, constituting the response variable, is affected by the prices from previous periods (so-called explanatory variables, which constitute response variables delayed by several periods).

The problem of setting prices for construction works is significant for both the investors and the contractor companies. During times of market instability, investors and those in charge of investment estimates are forced to perform a far-sighted price analysis and valuation of construction works. Before the calculation is started, it is necessary for the investor to conduct a detailed analysis and evaluation of the market and to become familiarized with economic and price related forecasts in the construction industry. It is only after such an assessment that it is possible within the framework of the initial assumptions for cost calculation to select the basis for setting prices and their levels [1,2]. Given the inability to include various forms of risk in investment estimates, it is unjustified to use average prices of production and works factors, especially in periods of uncertain and volatile market situation. 
When using a design-build system, which involves a long time between the planning stage and the realization of the project, taking into account expected prices of construction production factors may have a crucial impact on the successful execution of a project.

The examination of price forecasts is also fundamental for construction companies conducting long-term projects, where rapidly increasing prices result in execution problems. Due to the growing price pressure coming from subcontractors, combined with the rising prices of resources, materials, as well as wage expectations of physical and technical staff, general contractors are facing increasing costs resulting in a dramatic decline in the profitability of the construction industry.

Pricing strategies in the construction industry are mainly based on a cost-based approach. Newer models used for example in the oil industry [3] try to close the gap between the models and the real conditions of the bidder's decision-making process. Most modern and more advanced bidding strategy models require input information about competitors, such as their minimum and maximum markup, and some of them require information about customers/owners; most of the time, this information is not readily available.

Pricing strategies in construction include various pricing models for bid price determination, such as the Friedman-Gates models, expected utility models, risk-pricing model, and the crew-day, multiple regression, and fuzzy-set pricing models [4]. The techniques proposed so far are sophisticated, which may hinder their implementation in the construction industry. The methodology proposed by authors, based on the game theory against nature, allows for an easier and simpler application of pricing strategies by practitioners and engineers in the construction industry.

Owing to the negative consequences of increasing prices, contractors are forced to pay more attention to risk when calculating bids. It is a significant problem that requires reliable support methods. Consequently, the purpose of this study was to apply game theory against nature to select the optimal bid option for construction works. This optimal variant also allows for a balance (symmetry) between maximum profit and the probability of winning the contract. In an unstable market situation, a contractor can set the price of a bid with minimized risk related to a possible price increase by using game theory and projected unit prices of construction products. The example below illustrates the benefits resulting from the application of the proposed approach in reducing the uncertainty associated with the increase in the prices of construction products.

\section{Materials and Methods}

\subsection{Game against Nature Theory as a Decision-Making Tool}

Decision theory describes and explains the behavior of a complex system consisting of human and information resources. A decision is considered to be the choice of action to be taken to solve a particular problem. This selection is mostly based on the available information. A decision can be understood as a chain of interconnected activities, which is often referred to in the literature as a decision-making process. In the process, a decisionmaker makes an informed choice between several options all of which are considered to be achievable [5].

The result of the combination of a decision-maker's preferences and various decision options is the identification of a subjective solution that meets the decision-making criteria to the highest possible degree [5].

Many researchers are now interested in decision-making problems in construction [6]. A variety of decision-making methods have been used in selecting general contractors for construction works [7-10], choosing the optimal organizational options [11-13], or optimizing construction projects [14-16]. Decision-making models have also been used in the identification, analysis, and projection of investment risk [17-19] as well as in conflict management in works related contracts [20,21].

One of the decision-making tools, which finds application in the presented research problem, is game theory against nature. This concept should be understood as a model of a 
conflict situation presented numerically in the form of a win or a loss of individual parties, where the conflict parties aim to achieve different goals. In a given game, the players use specific strategies, and the result of the game is obtained depending on which strategy is applied, or which decision is made.

In a game against nature, one of the players is a person or an institution acting as a decision-maker. The other player is nature and can affect the outcome of the game to various degrees. Nature constitutes a set of conditions affecting the results of taken decisions, such as the unstable prices of construction products, which determine the choice of technology for the realization of individual construction activities. Games with nature are a special case of a two-player zero-sum game where nature is a passive player for whom winning is not important [22,23].

A set of possible choices that constitute the strategies of a decision-maker is formulated as:

$$
A=\left\{a_{1}, a_{2}, \ldots a_{i}\right\},
$$

while future states of nature, unknown at the time when the decision is made, are formulated as follows:

$$
S=\left\{s_{1}, s_{2}, \ldots, s_{j}\right\} .
$$

To resolve the game against nature, it is necessary to define either the function of the decision maker's loss $L(a, s)$ or the function of decision effectiveness $V(a, s)$. The first one is understood as the loss that will be incurred as a result of the choice of strategy $a$ in a given state of nature $s$, while the latter is understood as the decision-maker's victory which benefits from the decision a in the state of nature $s$.

To resolve a game of nature, it is required to apply certain decision-making criteria indicating the choice of the optimal decision which is to be made under the conditions of uncertainty concerning the future states of nature in a particular decision-making situation. The method of resolving the game with nature boils down to selecting one of the possible decision-making criteria.

In Wald's criterion [24], based on the loss function, the optimal decision corresponds to the lowest value of the maximum loss. On the other hand, when using the effectiveness function, the decision that maximizes the lowest value of the effectiveness function is the optimal one.

In the case of Hurwicz's criterion [25], the parameter $\alpha$ is adopted to determine the coefficient of pessimism (expectations as to the realization of a given state of nature) about the possible future states of nature. This criterion determines the optimal decision, which maximizes the average value of the lowest and highest decision efficiency function with the weights $\alpha$ and 1- $\alpha$ respectively. For a specific loss function, Hurwicz's criterion determines the optimal decision which minimizes the average value of the highest and the lowest loss function with the weights $\alpha$ and 1- $\alpha$ respectively.

Savage's criterion [26], which is based on Wald's criterion, refers to the minimum regret function (alternative loss function) resulting from wrong decisions for particular states of nature. The minimum regret function is formulated based on the decision effectiveness function or the loss function. According to Savage's criterion, it is first necessary to find the relative loss matrix (regret matrix). A loss is defined as the difference between the largest win possible in a particular state of nature, and the win corresponding to the decision currently under investigation.

$$
r_{i j}=\max _{i}\left\{v_{i j}\right\}-v_{i j},
$$

where: $r_{i j}$-elements of the alternative loss function matrix,

$v_{i j}$ - elements of the decision efficiency function matrix.

The optimal decision in Savage's criterion is the one that minimizes the greatest possible alternative loss. Thus, the next step (operating on the regret matrix) is to determine 
the maximum loss for each strategy and choose the strategy for which the maximum loss will be the smallest.

$$
V(a, s)=\min _{a \in A} \max _{s \in S} \bar{V}(a, s)=\min _{i} \max _{j} r_{i j}
$$

where $\bar{V}(a, s)$ is an alternative loss function based on the decision effectiveness function $V(a, s)$.

Game theory makes it possible to mathematically present and resolve conflict situations in the management of construction projects which require continuous decisionmaking. One is therefore allowed to make the most beneficial choice from a set of various options [27].

Grzyl et al. [20] used game theory to indicate the best strategy leading to winning legal trials in the event of a conflict between the general contractor of construction works and the investor. Based on the developed game model, the expected profits for players were calculated and the probability of winning the dispute was determined, which allowed the general contractor to choose the best strategy.

Barough et al. [28] investigated the application of game theory in dispute resolution in construction project management. Two decision-making models were developed to analyze how the selected decisions affected the other participants of the construction project.

To solve complex technical and human-related problems in negotiations between the participants of an investment process, San Cristóbal [21] developed a model based on game theory, which made it possible to determine the actions responsible for project delays and the distribution of costs among them.

Dong-hong and Xi-yan [29] developed a decision-making game model for analyzing the phenomena occurring in tender procedures. The results of the analysis increased the probability of winning the tender by accurately estimating the costs of the project. The scholars' work also demonstrates a method to boost the competitiveness of a tender participant.

Peldschus et al. [11] used game theory for a balanced multi-criteria assessment. The study aimed to select the optimal variant of the construction site.

The example of a game against nature presented in this paper is an alternative, widely applicable approach to the problem of decision-making related to the choice of the optimal cost estimate option for construction works.

\subsection{Forecasting Economic Phenomena}

The information about future states of certain phenomena plays an important role in supporting decision-making in the economy, as it reduces the impact of business-related risks. The necessity to take inflationary or deflationary risks into account when negotiating and determining contractual remuneration for projects that are expected to be performed over long periods is the reason why various types of forecasts are used by many researchers [30].

Jaśkowski et al. [31] proposed a model enabling a user to determine the volume of orders and to select supply channels for building materials. To take account of irregular fluctuations in the prices of building materials, they applied fuzzy logic and analyzed different scenarios for future price changes. Through this solution, it was possible to develop an optimal supply plan regardless of the actual scenario of material price changes, as well as to reduce the total cost of resources.

Czarnigowska and Sobotka [32] investigated the possibility of using a simple regression model to predict the duration of road construction based on early cost forecasts. The studies confirmed the universal nature of Bromilow's time-cost model and its statistical correctness.

Leśniak and Juszczyk, in turn, [33] developed a regression model, based on artificial neural networks, which makes it possible to predict overhead construction costs. The 
developed method allowed for a more accurate estimate of the costs at an early stage of the construction project.

Kim et al. [19] developed a structural equation model (SEM) to estimate the success of international construction projects which are difficult to evaluate. By comparing it with multiple regression analysis and artificial neural networks, SEM allows for a more accurate result estimation due to its ability to continuously and accurately take into account various risk factors. Moreover, the use of SEM provides a possibility of a visual representation of how variables are related to each other, to facilitate the understanding of the complex system and its key assumptions, which the success of a project depends on.

Tatiya et al. [34] investigated the problem of demolition and the storage of waste resulting from the abandoning of residential, service, or industrial buildings. The phenomenon is becoming increasingly common due to the economic collapse in many countries. As opposed to demolition, deconstruction represents a balanced approach to the systematic dismantling of buildings, which allows the materials to be reused and recycled. However, the rising costs are the major problem that stops decision-makers from taking advantage of deconstruction. To solve the problem, the authors developed a novel cost forecasting model based on artificial intelligence. Studies indicate that the accuracy of the proposed forecasting model is greater than $95 \%$ and that the model offers a way to make the deconstruction cost lower than the demolition cost.

In the construction industry, a big problem is the complexity of the cost calculation. The price for construction works includes prices of many materials, machines, workers of various professional specialties. Even with price forecasts made with more reliable methods than linear regression, it should be taken into account that errors in price forecasts of many materials will accumulate. Uncertainty of the decision-making situation also increases the issue of accuracy of input estimates.

Forecasting and game theory are both effective tools that may be used to support finance-related decision-making and reduce the impact of risk factors in the management of construction projects.

Construction sector productivity is also of great importance for the government and policymakers because it determines a nation's future living standards and creates a competitive business environment. Factors that affect productivity include management and control, workforce, financial, external, project, and material and equipment. According to previous research, the most important is the management team competency level and workforce quality in enhancing labor productivity. Moreover, client support and efforts by government authorities are found to be significant for labor productivity improvements [35-37].

Searching for effective decision-making tools is crucial for the construction industry. Effective management of a construction company allows achieving strategic goals such as profit maximization, variable cost coverage, and revenue maximization.

Taking into consideration the foregoing facts, a thorough step-by-step procedure of the proposed method, as shown in Figure 1, can be accurately presented through the following basic steps: 


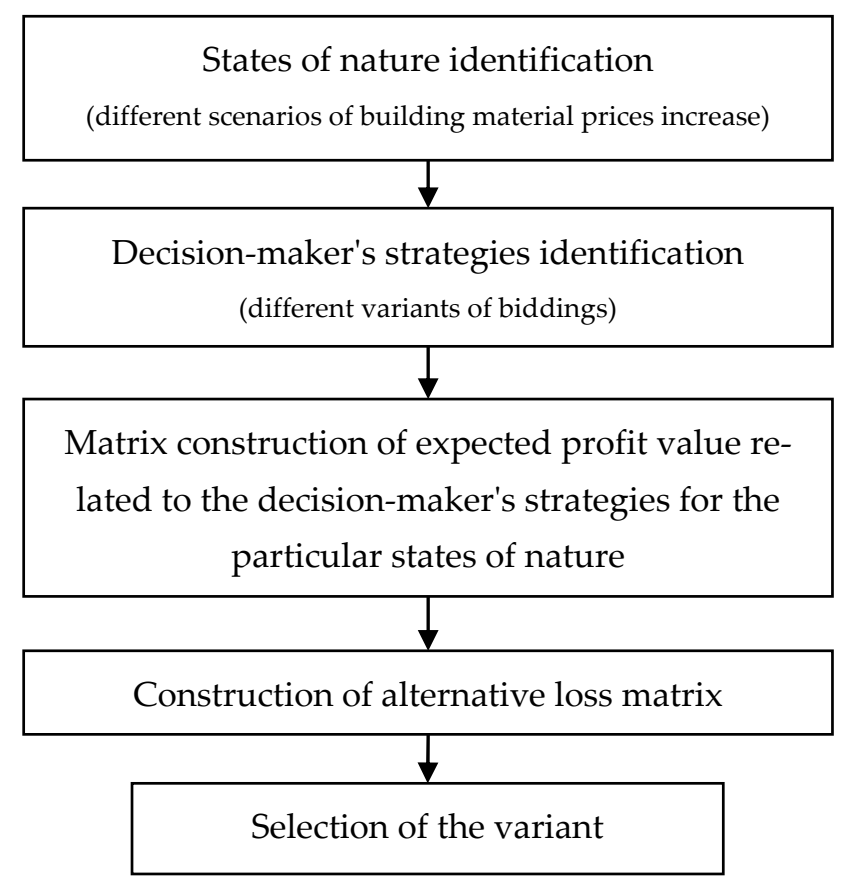

Figure 1. The computational procedure of the proposed method.

\section{Results}

The construction industry in most countries of the world is one of the highest competitive, high-risk, and profit margins generally low when compared to other economic areas. Therefore, pricing is one of the most important aspects of marketing in the construction industry. However, unlike in other industries, transactions and contracting in the construction industry are conducted through a competitive bidding process so pricing mostly takes place in a bidding process. Most often only one pricing approach is used in the construction industry: cost-based pricing. A typical procedure of cost-based pricing involves estimating project costs and then applying a markup of profit. This approach was proposed by many researchers [38-40]

The proposed approach studies the situation in which a contractor is considering participating in a tender procedure for the construction of a school building with a gymnasium, which is to be realized with the use of modernized traditional technology. Due to the investor's budget constraints and the adopted design and build system, the project cannot start earlier than a year from now. When submitting the tender under such circumstances, the contractor must consider a possible increase in the prices of the construction products which will be used in the future. To achieve maximum profit in an uncertain market situation, it is advisable to take the predicted price level of building materials into account.

In the case under study, the analysis includes the prices of building materials as well as the plumbing and electrical installations. Due to the uncertain economic situation, the contractor preparing a bid should consider various scenarios for the increase in the price of materials: the pessimistic one, the optimistic one, and the most probable one. The price forecasts were increased and decreased symmetrically by an ex-post error, thus obtaining, in turn, a pessimistic and optimistic scenario. The most probable scenario, on the other hand, is a price increase equal to the value presented in the forecast. The percentage values of the forecasts and their ex-post errors were established based on market reports prepared by Polish construction price book publishers (Figure 2).

The econometric models used to estimate the forecasts and the errors made it possible to obtain high values of determination coefficients (about 0.8), which leads to a conclusion that they represent an effective tool for forecasting the prices of construction products. A summary of the forecasts and the ex-post errors is presented in Table 1. 


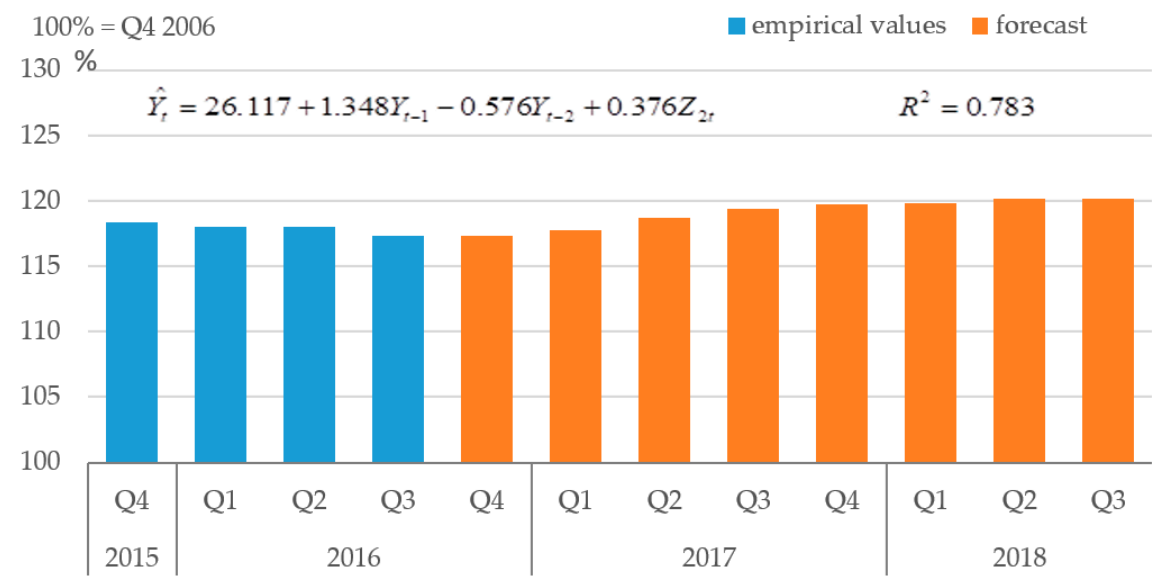

Figure 2. An example of a price change forecasts of building materials with an econometric model in the function form and a coefficient of determination, adopted for research.

Table 1. A summary of the forecasts and the ex-post errors of the prices of construction products which were analyzed.

\begin{tabular}{ccc}
\hline & Forecast (\%) & Ex-Post Error (\%) \\
\hline Construction materials & 1.7 & 0.834 \\
Plumbing materials & 2.2 & 0.414 \\
Electrical materials & 8.1 & 4.742 \\
\hline
\end{tabular}

The value of the bid price $b$ can be presented as follows:

$$
b_{i}=c_{i}+f_{i}
$$

where: $c_{i}$-the cost of the completion of works, $f_{i}$ - bidder's profit.

In accordance with the method of bid presentation in public tenders in Poland, the cost of the works consists of the direct $\operatorname{costs} c_{i}{ }^{d}$ and the indirect $\operatorname{costs} c_{i}{ }^{\text {ind }}$ :

$$
c_{i}=c_{i}^{d}+c_{i}^{\text {ind }} .
$$

The indirect costs are most often expressed as a percentage of the sum of the labor cost and the plant cost:

$$
c_{i}^{\text {ind }}=w_{i}^{\text {ind }}\left(c_{i}^{L}+c_{i}^{P}\right),
$$

where $w_{i}^{\text {ind }}$ represents a rate of overhead applied by a decision-maker individually.

Direct costs consist of the labor $\operatorname{costs} c_{i}{ }^{L}$, the materials costs $c_{i}{ }^{M}$, and the plant costs $c_{i}^{P}$ :

$$
c_{i}^{d}=c_{i}^{L}+c_{i}^{M}+c_{i}^{P} .
$$

The cost of materials constitutes the sum of the products of the number of works, the norms for the consumption of materials, and the unit prices of the materials.

In accordance with the Polish cost estimate guidelines and the industry practice, profit is most often referred to as the product of the profit rate $w_{i}^{f}$ and the sum of the labor costs $c_{i}^{L}$, the plant $\operatorname{costs} c_{i}^{P}$, and the indirect $\operatorname{costs} c_{i}^{i n d}$ :

$$
f_{i}=w_{i}^{f}\left(c_{i}^{L}+c_{i}^{P}+c_{i}^{i n d}\right),
$$

where $w_{i}^{f}$ is the profit rate adopted by a decision-maker individually. This approach is also used in market reports prepared by Polish construction price book publishers.

By factoring in real prices of construction products $\hat{c}_{i}^{M}$, it is possible to estimate the loss resulting from the difference $c_{i}^{M}$ between the prices that were assumed at the time of 
the bid development and the real prices at the start of the project. In practice, one assumes the prices which are at an average level or the prices which are the most likely according to forecasts. Thus, a bidder preparing an offer can minimize the risks connected with the unstable situation in the market of construction materials. Taking the Formulas (5)-(9) into account, the contractor' profit mark-up can be determined as follows:

$$
\begin{aligned}
F\left(a_{i}, s_{j}\right)=\sum_{i=1}^{m} F_{i} & =\sum_{i=1}^{m}\left[\hat{c}_{i}^{M}\left(s_{j}\right)-c_{i}^{M}+f_{i}\left(a_{i}\right)\right], \\
i & =1,2, \ldots, m, \\
j & =1,2, \ldots, n .
\end{aligned}
$$

The parameter $i$ refers to the number of possible choices that are the strategies of the decision-maker. In this study, these are different variants of the decision maker's offers depending on the level of profit. Parameter $j$, on the other hand, describes future states of nature, unknown at the time of decision making. In this paper, there are different scenarios of building material price increases.

The expected profit $E(F)$ is defined as the product of the contractor's mark-up, minus the loss resulting from the increase in the price of building materials and the probability of winning, based on the contractor's winning experience in past tender procedures. Friedman [41] presented a recursive algorithm allowing to determine the approximate values of the profit rate (and the bid price) ensuring the greatest probability of winning the tender assuming that it has a normal distribution. This assumption has been verified in the papers $[42,43]$ as well as the range of values and possibilities for the bids ranging from $5 \%$ and $11 \%$ of profit margins. The probability curve was assumed based on the results of the study [43].

The optimal decision will correspond to the expected value of the profit depending on the strategy adopted by the decision-maker:

$$
E(F)=F\left(a_{i}, s_{j}\right) * P\left(a_{i}\right) .
$$

Game theory against nature offers an option to select a strategy that minimizes the maximum loss associated with the increase in the price of materials in different states of nature, which will correspond to the situation on the market of building materials. The states of nature were determined based on three scenarios (optimistic, pessimistic, and most probable) of an increase in the prices of building materials, plumbing, and electrical installations. To determine the number of all possible scenarios for various price levels of building materials, the Cartesian product of three 3-element sets was calculated:

$$
\begin{gathered}
X \times Y \times Z=\left\{\left(x_{n}, y_{n}, z_{n}\right): x_{n} \in X \wedge y_{n} \in Y \wedge z_{n} \in Z\right\}, n=1,2,3 \\
X=\left\{x_{1}, x_{2}, x_{3}\right\}, Y=\left\{y_{1}, y_{2}, y_{3}\right\}, Z=\left\{z_{1}, z_{2}, z_{3}\right\}
\end{gathered}
$$

where: $x$-increase in the price of building materials,

$y$-increase in the price of plumbing materials,

$z$-increase in the price of electrical materials,

1 -optimistic scenario,

2-pessimistic scenario,

3-most probable scenario.

The result provided a set of 27 ordered three-element subsets of projected prices reflecting the number of the states of nature: $S=\left\{s_{1}, s_{2}, \ldots, s_{j}\right\}, s_{j}=\left(x_{n}, y_{n}, z_{n}\right), j=1,2, \ldots$, $27, n=1,2,3$.

The decision-maker's strategies, presented in Table 2, reflect the levels of the profit rate that will allow the expected profit value $E(F)$ to be achieved: $A=\left\{a_{1}, a_{2}, \ldots, a_{i}\right\}, a_{i}=$ $\{5 \%, 5.5 \%, 6 \% \ldots, 11 \%\}, m=1,2, \ldots, 13$. 
Table 2. The expected profit value [EUR] is related to the decision-maker's strategies for the particular states of nature.

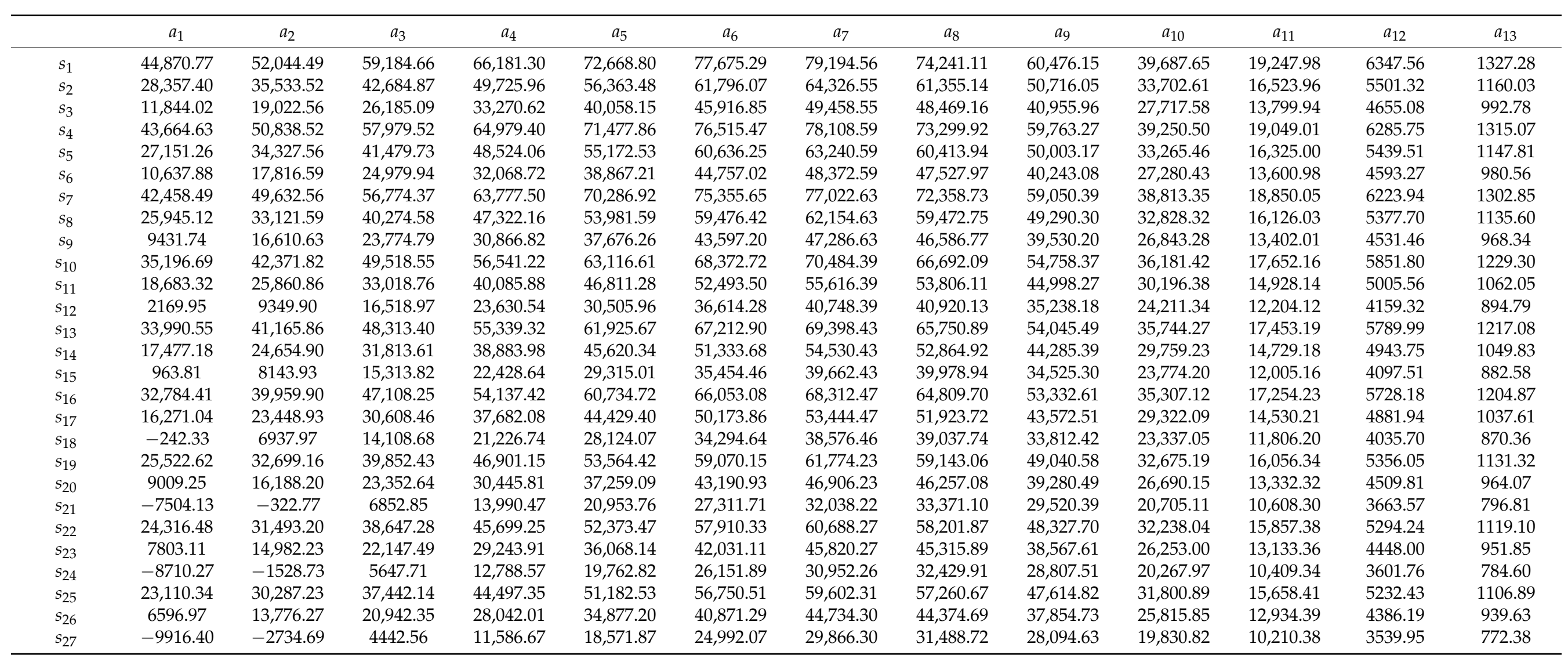


For example, following Equations (9) and (10), the expected profit value related to the a1 strategy for the s1 state of nature was calculated by real price of construction products equals $1,826,537.09$ EUR, the price that was assumed at the time of the bid equals 1,799,593.88 EUR, the direct costs equal 2,669,556.80 EUR, the indirect costs equal $566,345.86 \mathrm{EUR}$, the profit rate equal $5 \%$ and the probability of winning equal $99.99675 \%$, which resulted in the amount of 44,870.77 EUR:

$[5 \% \times(2,669,556.80-1,799,593.88+566,345.86)+1,799,593.88] \times 99.99675 \%=44,870.77[\mathrm{EUR}]$

To select the optimal decision, Savage's criterion is used. It is assumed by the contractor that making a decision involves the risk of a mistake which may lead to a loss resulting from failing to select the optimal variant. The criterion minimizes the potential relative loss. The decision is made in two steps. The first one requires a regret matrix reflecting the value of relative losses to be created $r_{i j}$ (Table 3).

It is then necessary to select the column with the lowest maximum: $V(a, s)=$ $\min _{a \in A} \max _{s \in S} \bar{V}(a, s)=\min _{i} \max _{j} r_{i j}=1622.41$. A contractor whose target is to minimize lost benefits should choose the $a_{7}$ strategy with a profit of $8 \%$, as in this case, the potential relative loss (relative to the best possible state of nature) is the smallest.

Following a more cautious criterion focused on risk minimization (Wald's criterion), the contractor should opt for the $a_{8}$ strategy with a profit rate of $8.5 \%$. On the other hand, using Hurwicz's criterion, the optimal decision depends on the value of the degree of pessimism assumed:

- $\quad$ for the value range $0<\alpha<0.75$-the optimal strategy is the strategy $a_{7}$;

- for the value range $0.75<\alpha<1$-the optimal strategy is the strategy $a_{8}$. 
Table 3. Alternative loss matrix.

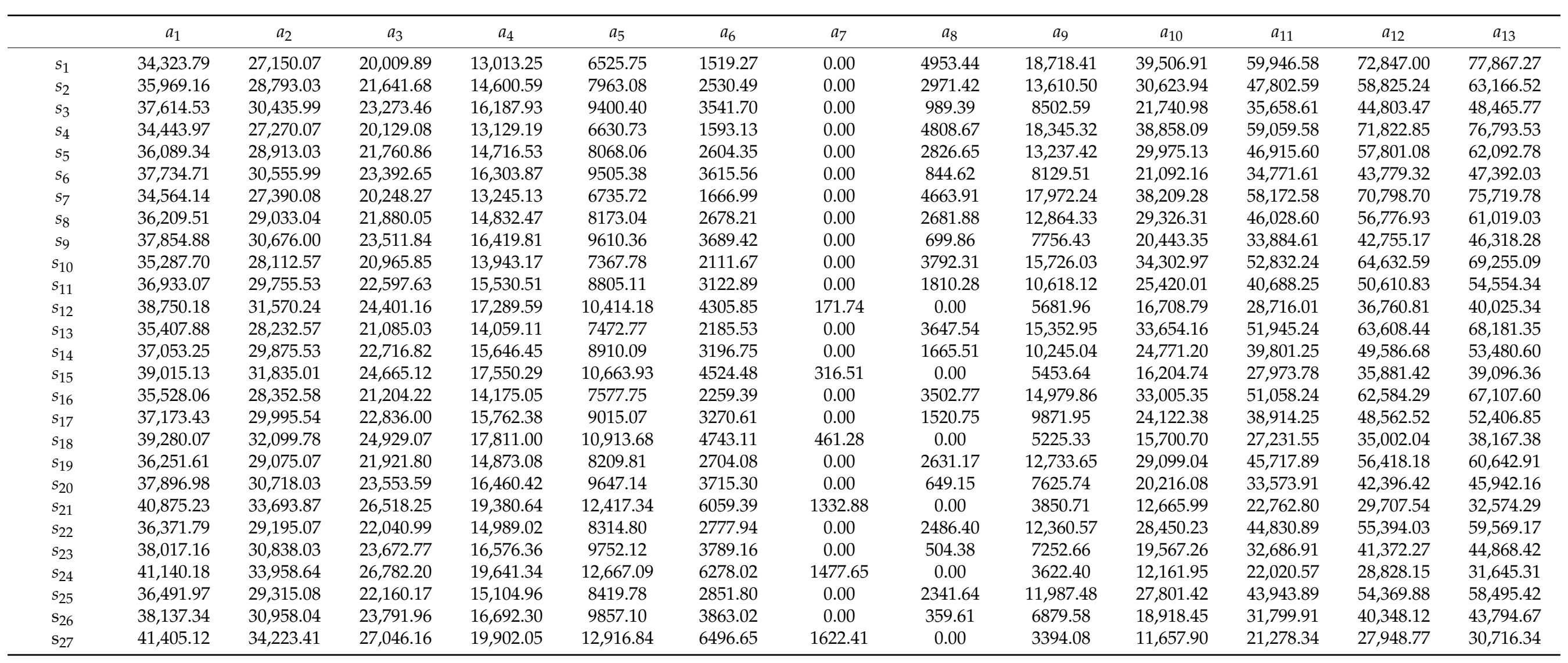




\section{Discussion and Conclusions}

The effective development of bid pricing requires a detailed analysis of market conditions, trends observed in particular material markets, and projected changes in legislation. The conducted studies confirmed the effectiveness of the proposed methods of supporting decision-making by indicating the optimal strategy to reduce financial losses in times of uncertain market situation. Most modern and more advanced bidding strategy models require input information about the competitors, which is very difficult to obtain. Smaller companies with a limited budget are not able to invest in forecasting studies, so they are often forced to use publicly available statistical data. In Poland, such analyses are published in price publications and industry journals. These commonly available data were used in this study which allows for easier application of the proposed methodology to the construction industry.

The conducted research allowed obtaining a pricing strategy which, with maximum profit for the contractor, keeps a high probability of winning the contract in an uncertain economic situation. A significant part of the research on bid pricing is based, among others, on the Friedman-Gates models, expected utility models, risk-pricing model, and the crewday, multiple regression, and fuzzy-set pricing models. The application of the game theory against nature allows for the easier and simpler implementation of pricing strategies by practitioners and engineers in the construction industry. The presented methods used to identify and protect against the risks associated with uncontrolled price increases are extremely important especially for the companies engaged in long-term projects.

The results of the analysis made it possible to identify the optimal option in light of the adopted criteria. However, it is necessary to remember that the result depends on the projected price values of building materials. If the assumptions are changed, a new, possibly more favorable solution than the one obtained in the study may become available. For this reason, an analysis of the sensitivity of the results in the case of the prices of construction products reaching different values than expected was performed. As a result, it turned out that the change in material costs may have a significant impact on the contractor's profit. In the case of the chosen option, a $4 \%$ increase in prices is enough to reduce the contractor's profit by almost a half.

Given the obtained results, it appears necessary to analyze the remaining bid price components and to study the impact which they have on the level of profit. To determine the risk of profit reduction, a contractor should additionally assess the probability of an increase in the prices of production factors, which will constitute the direction of further research.

Author Contributions: Conceptualization, P.J. and Ł.R.; Data curation, Ł.R.; Writing-Original draft, Ł.R.; Writing—Review \& editing, Ł.R. and P.J. All authors have read and agreed to the published version of the manuscript.

Funding: The work was financed by the Polish Ministry of Science and Higher Education FNM63/ILT. Institutional Review Board Statement: Not applicable.

Informed Consent Statement: Not applicable.

Data Availability Statement: Data generated or analyzed during the study are available from the corresponding author by request.

Conflicts of Interest: The authors declare no conflict of interest.

\section{References}

1. Magnussen, O.M.; Olsson, N.O.E. Comparative Analysis of Cost Estimates of Major Public Investment Projects. Int. J. Proj. Manag. 2006, 24, 281-288.

2. Chou, J.-S. Generalized Linear Model-Based Expert System for Estimating the Cost of Transportation Projects. Expert Syst. Appl. 2009, 36 Pt 1, 4253-4267.

3. Haile, P.; Hendricks, K.; Porter, R. Recent US offshore oil and gas lease bidding: A progress report. Int. J. Ind. Organ. 2010, 28, 390-396. 
4. Mochtar, K.; Arditi, D. Alternate pricing strategies in construction. Civ. Eng. Dimen. 2000, 2, 56-64.

5. Simon, H. Theories of Decision-Making in Economics and Behavioral Science. Am. Econ. Rev. 1959, 49, $253-283$.

6. Kapliński, O.; Tamošaitienè, J. Game Theory Applications in Construction Engineering and Management. Technol. Econ. Dev. Econ. 2010, 16, 348-363.

7. Tomczak, M.; Jaśkowski, P. New Approach to Improve General Contractor Crew's Work Continuity in Repetitive Construction Projects. J. Constr. Eng. Manag. 2020, 146, 04020043.

8. Zavadskas, E.K.; Turskis, Z.; Tamošaitienè, J. Contractor Selection of Construction in a Competitive Environment. J. Bus. Econ. Manag. 2008, 9, 181-187.

9. Tomczak, M.; Jaśkowski, P. Application of Type-2 Interval Fuzzy Sets to Contractor Qualification Process. KSCE J. Civ. Eng. 2018, 22, 2702-2713.

10. Radziszewska-Zielina, E. The application of multi-criteria analysis in the evaluation of partering relations and the selection of a construction company for the purposes of cooperation. Arch. Civ. Mech. Eng. 2016, 62, 167-182.

11. Peldschus, F.; Zavadskas, E.K.; Turskis, Z.; Tamosaitiene, J. Sustainable Assessment of Construction Site by Applying Game Theory. Eng. Econ. 2010, 21, 223-237.

12. Yang, Y.-P.; Wang, M.-J. Analysis on the Interests of Construction Parties in Project Management Model Based on the Game Theory. In Proceedings of the 2009 Chinese Control and Decision Conference, Guilin, China, 17-19 June 2009.

13. Szafranko, E.; Srokosz, P. Applicability of the theory of similarity in an evaluation of building development variants. Autom. Constr. 2019, 104, 322-330. [CrossRef]

14. Biruk, S.; Rzepecki, Ł. Simulation Model for Resource-Constrained Construction Project. Open Eng. 2019, 9, 37. [CrossRef]

15. Tomczak, M.; Rzepecki, L. Evaluation of Supply Chain Management Systems Used in Civil Engineering. IOP Conf. Ser. Mater. Sci. Eng. 2017, 245, 072005. [CrossRef]

16. Tomczak, M. Modeling of the Harmonization Method for Executing a Multi-Unit Construction Project. Open Eng. 2019, 9, $282-291$. [CrossRef]

17. Anysz, H.; Buczkowski, B. The association analysis for risk evaluation of significant delay occurrence in the completion date of construction project. Int. J. Environ. Sci. Technol. 2019, 16, 5369-5374. [CrossRef]

18. Plebankiewicz, E.; Wieczorek, D. Adaptation of a Cost Overrun Risk Prediction Model to the Type of Construction Facility. Symmetry 2020, 12, 1739. [CrossRef]

19. Kim, D.Y.; Han, S.H.; Kim, H.; Park, H. Structuring the prediction model of project performance for international construction projects: A comparative analysis. Expert Syst. Appl. 2009, 36, 1961-1971. [CrossRef]

20. Grzyl, B.; Apollo, M.; Kristowski, A. Application of Game Theory to Conflict Management in a Construction Contract. Sustainability 2019, 11, 1983. [CrossRef]

21. San Cristóbal, J.R. The Use of Game Theory to Solve Conflicts in the Project Management and Construction Industry. Int. J. Inf. Syst. Proj. Manag. 2015, 3, 43-58.

22. Papadimitriou, C.H. Games against Nature. J. Comput. Syst. Sci. 1985, 31, 288-301. [CrossRef]

23. Jaworski, K.M. Metodologia Projektowania Realizacji Budowy, 2nd ed.; PWN: Warsaw, Poland, 2009. (In Polish)

24. Wald, A. Statistical Decision Functions; Wiley: Oxford, UK, 1950; p. 179.

25. Hurwicz, L. Optimality Criteria for Decision Making Under Ignorance. Statistics 1951, 370. Available online: https: / / cowles.yale. edu/sites/default/files/files/pub/cdp/s-0370.pdf (accessed on 14 January 2021).

26. Savage, L.J. The Theory of Statistical Decision. J. Am. Stat. Assoc. 1951, 46, 55-67. [CrossRef]

27. Peldschus, F. Experience of the Game Theory Application in Construction Management. Technol. Econ. Dev. Econ. 2008, 14, 531-545. [CrossRef]

28. Barough, A.S.; Shoubi, M.V.; Skardi, M.J.E. Application of Game Theory Approach in Solving the Construction Project Conflicts. Procedia-Soc. Behav. Sci. 2012, 58, 1586-1593. [CrossRef]

29. Dong-hong, C.; Xi-yan, Z. Application of Game Theory on Bidding Price Decision. In Proceedings of the 200916 th International Conference on Industrial Engineering and Engineering Management, Beijing, China, 21-23 October 2009; pp. 58-61.

30. Ntakaris, A.; Mirone, G.; Kanniainen, J.; Gabbouj, M.; Iosifidis, A. Feature Engineering for Mid-Price Prediction With Deep Learning. IEEE Access 2019, 7, 82390-82412. [CrossRef]

31. Jaśkowski, P.; Sobotka, A.; Czarnigowska, A. Decision Model for Planning Material Supply Channels in Construction. Autom. Constr. 2018, 90, 235-242. [CrossRef]

32. Czarnigowska, A.; Sobotka, A. Time-Cost Relationship for Predicting Construction Duration. Arch. Civ. Mech. Eng. 2013, 13, 518-526. [CrossRef]

33. Leśniak, A.; Juszczyk, M. Prediction of Site Overhead Costs with the Use of Artificial Neural Network Based Model. Arch. Civ. Mech. Eng. 2018, 18, 973-982. [CrossRef]

34. Tatiya, A.; Zhao, D.; Syal, M.; Berghorn, G.H.; LaMore, R. Cost Prediction Model for Building Deconstruction in Urban Areas. J. Clean. Prod. 2018, 195, 1572-1580. [CrossRef]

35. Shoar, S.; Banaitis, A. Application of Fuzzy Fault Tree Analysis to identify factors influencing construction labor productivity: A high-rise building cas study. J. Civ. Eng. Manag. 2019, 25, 41-52. [CrossRef]

36. Gutiérrez-Ruiz, A.M.; Valcarce-Ruiz, L.; Becerra-Vicario, R.; Ruiz-Palomo, D. Identifying Industrial Productivity Factors with Artificial Neural Networks. J. Sci. Ind. Res. 2020, 79, 534-536. 
37. Durdyev, S.; Ismail, S.; Kandymov, N. Structural equation model of the factors affecting construction labor productivity. J. Constr. Eng. M 2018, 144, 1-11. [CrossRef]

38. Fayek, A. Competitive bidding strategy model and software system for bid preparation. J. Constr. Eng. Manag. 1998, 124, 1-10. [CrossRef]

39. Ioannou, P.G.; Leu, S.S. Average-bid method-competitive bidding strategy. J. Constr. Eng. Manag. 1993, 119, 131-147. [CrossRef]

40. Moselhi, O.; Hegazy, T.; Fazio, P. DBID: Analogy-based DSS for bidding in construction. J. Constr. Eng. Manag. 1993, 119, 466-479. [CrossRef]

41. Friedman, L.A. Competitive-Bidding Strategy. Oper. Res. 1956, 4, 104-112. [CrossRef]

42. Jaśkowski, P.; Czarnigowska, A. Contractor's Bid Pricing Strategy: A Model with Correlation among Competitors' Prices. Open Eng. 2019, 9, 159-166. [CrossRef]

43. Jaśkowski, P.; Biruk, S.; Czarnigowska, A. Strategy for Mark-up Definition in Competitive Tenders for Construction Work. IOP Conf. Ser. Mater. Sci. Eng. 2019, 471, 112060. [CrossRef] 